\title{
Detection of replication-defective hepatitis A virus based on the correlation between real-time polymerase chain reaction and ELISA in situ results
}

\author{
Alyne Moraes Costa, Luciane Almeida Amado, Vanessa Salete de Paula/ ${ }^{+}$ \\ Laboratório de Desenvolvimento Tecnológico em Virologia, Instituto Oswaldo Cruz-Fiocruz, Rio de Janeiro, RJ, Brasil
}

\begin{abstract}
ELISA in situ can be used to titrate hepatitis A virus (HAV) particles and real-time polymerase chain reaction (RT-PCR) has been shown to be a fast method to quantify the HAV genome. Precise quantification of viral concentration is necessary to distinguish between infectious and non-infectious particles. The purpose of this study was to compare cell culture and RT-PCR quantification results and determine whether HAV genome quantification can be correlated with infectivity. For this purpose, three stocks of undiluted, five-fold diluted and 10-fold diluted HAV were prepared to inoculate cells in a 96-well plate. Monolayers were then incubated for seven, 10 and 14 days and the correlation between the ELISA in situ and RT-PCR results was evaluated. At 10 days post-incubation, the highest viral load was observed in all stocks of HAV via RT-PCR $\left(10^{5}\right.$ copies $\left./ \mathrm{mL}\right)(p=0.0002)$, while ELISA revealed the highest quantity of particles after 14 days (optical density $=0.24, p<0.001$ ). At seven days post-infection, there was a significant statistical correlation between the results of the two methods, indicating equivalents titres of particles and HAV genome during this period of infection. The results reported here indicate that the duration of growth of $H A V$ in cell culture must be taken into account to correlate genome quantification with infectivity.
\end{abstract}

Key words: hepatitis A virus - replication-defective - RT-PCR - ELISA in situ

The quantification of infectious particles in samples and in cell culture is an important tool in virology. Viral titres can be estimated based on cell culture methods that require serial dilution to determine infectivity and are expressed as plaque forming units or cell culture infective doses. Both methods are laborious and time consuming (Khatib et al. 1980) and the sensitivity decreases with low numbers of viral particles. Determining accurate and precise titres is a challenge for viruses for which cell culture is not available or viral growth is limited, but this quantification is critical in vaccine production and quality control, gene therapy and the investigation of antivirals (Forcic et al. 2009).

Hepatitis A virus (HAV) is a representative member of the genus Hepatovirus within the family Picornaviridae (Minor 1991). The 27-32 nm particle is non-enveloped and contains a single strand of positive-sense RNA as its genome (Siegl 1982). Cell propagation methods are the method of choice to demonstrate viral infectivity (Donia et al. 2009). However, since it was first adapted to cell culture (Provost 1979), HAV has been demonstrated to replicate slowly, with culture times of 10-14 days in most reported systems. HAV also establishes persistent infections in tissue culture (Provost 1979, Wheeler et al. 1986), but the slow, non-cytopathic growth of HAV has

Financial support: CNPq, FIOCRUZ

+Corresponding author: vdepaula@ioc.fiocruz.br

Received 29 February 2012

Accepted 5 September 2012 hampered its study in tissue culture and its quantification. Subsequent methods developed to assay HAV in tissue culture include the radioimmunofocus assay (RIFA) (Lemon et al. 1983), in situ RIFA and the fluorescent focus assay (Siegl et al. 1984); all three procedures have been commonly used to monitor the production of HAV antigen as an indirect indicator of viral growth (Purcell et al. 1976, Siegl et al. 1984). Few assay methods have been developed for HAV titration (Lemon et al. 1983, Richards $\&$ Watson 2001, Villar et al. 2004, Konduru et al. 2008).

Currently, molecular tests, including real-time-polymerase chain reaction (RT-PCR), have been successfully applied in viral quantification and these tests allow rapid, specific detection. The molecular detection of viruses, which is now becoming more widely available, does not require the lengthy incubation period needed for viral isolation from cell culture, may require less technical expertise and is useful for viruses that do not proliferate in standard cell culture (Leland \& Ginocchio 2007). However, the detection of viral genomes in cell culture using RT-PCR is not sufficient to distinguish between infectious and non-infectious particles and does not guarantee that every copy of detected RNA corresponds with a complete viral particle. In currently available hepatitis A vaccines, the virus is grown in cell culture and then inactivated. The monitoring of viral inactivation may be achieved by leveraging an established pattern of correlation between the number of amplified copies of the viral genome, determined by RT-PCR and the number of viral particles titrated by ELISA in situ. A comparative study aimed at evaluating the correlation between the numbers of viral particles and HAV genomes, measured by ELISA in situ and RT-PCR, was performed to evaluate the possibility of rapidly and efficiently determining HAV titres. 


\section{MATERIALS AND METHODS}

Foetal rhesus kidney-4 (FRhK-4) cell culture and $H A V$ - A continuous FRhK-4 cell line was grown at $37^{\circ} \mathrm{C}$ in $175 \mathrm{~cm}^{2}$ disposable Falcon flasks containing 199 medium supplemented with $10 \%$ heat-inactivated foetal bovine serum (FBS), 2 mM L-glutamine, $0.1 \mathrm{mM}$ MEM non-essential amino acids, $25 \mathrm{mM}$ HEPES, $0.18 \%$ sodium bicarbonate, $100 \mathrm{U} / \mathrm{mL}$ penicillin and $100 \mu \mathrm{g} / \mathrm{mL}$ streptomycin (Sigma Chemical Co). Flat-bottomed 96-well microtitre plates (tissue culture grade, Nunc Inc Naperville, IL, USA) were seeded with $100 \mu \mathrm{L}$ of a suspension of FRhK-4 cells prepared in growth medium $\left(10^{4.5}\right.$ cells/ $\mathrm{mL})$. After incubation at $37^{\circ} \mathrm{C}$ in a $5 \% \mathrm{CO}$, atmosphere for $24 \mathrm{~h}$ until confluence was just reached, $100 \mu \mathrm{L}$ dilutions of virus sample prepared in 199 medium supplemented with 2\% heat-inactivated FBS were added to test eight wells per dilution without removal of the growth medium.

HAV plate assay - Three aliquots of HAV (HAF-203) (undiluted, 5-fold diluted and 10-fold diluted) were prepared to inoculate the 96-well plate to compare the quantification of HAV by the tissue culture infective dose $\left(\mathrm{TCID}_{50}\right)$ method and RT-PCR. Two columns of uninfected wells were included on each plate as negative controls and one extra column was included to blank the plate reader. Monolayers were then incubated for seven, 10 and 14 days. The reproducibility of both tests was evaluated by performing the assays in triplicate and on different days.

ELISA in situ - To quantify the infectivity of HAV in cell culture, ELISA in situ was performed as previously described by Villar et al. (2004). After days 7, 10 and 14, the medium was removed and the cells were fixed using $100 \mu \mathrm{L}$ per well of a 1:1 mixture of acetone and methanol at $4^{\circ} \mathrm{C}$ for $5 \mathrm{~min}$. The fixative was removed and the monolayers were allowed to dry uncovered at room temperature for at least $2 \mathrm{~h}$. The presence of virus-specific antigen was detected using the conjugate diluted 1:8000 with phosphate buffered saline (PBS) $/ 0.5 \%$ bovine albu- $\min (\mathrm{w} / \mathrm{v})$. The conjugate $(100 \mu \mathrm{L})$ was added to each test and uninfected well but not to the blank wells. After incubation of the cells at $37^{\circ} \mathrm{C}$ for $1 \mathrm{~h}$, the antibody solution was removed and the monolayers were washed four times with PBS plus $0.1 \%$ Tween 20 (w/v) $(300 \mu \mathrm{L} /$ well) using an automated plate washer. Immediately after washing, bound antibody was detected using hydrogen peroxide and tetramethylbenzidine. The colour change was monitored visually and stopped after $15 \mathrm{~min}$ by the addition of $100 \mu \mathrm{L}$ of $1 \mathrm{M}$ sulphuric acid per well. The absorbance of the plates was then read at $450 \mathrm{~nm}$ and a positive/negative ratio was determined using uninfected wells as the negative value. The titre of infectious virus was determined according to the method of Reed and Muench (1938), which is based on the TCID $_{50}$ endpoint.

Extraction of viral RNA from cell culture supernatants - A TaqMan RT-PCR assay was performed to quantify HAV genomes as previously described by de Paula et al. (2009). RNA was extracted from cells in microplates using the SV Total RNA Isolation System (Promega Corporation, Madison, WI), which specifically purifies viral RNA from tissues and cultured cells. This method is based on a lysis-centrifugation process, followed by column filtration through a silica membrane in an RNasefree environment. The trypsinised cells were pelleted by centrifugation at $500 \mathrm{~g}$ for $5 \mathrm{~min}$ and the supernatant was discarded. The whole cell pellets were disrupted by adding $300 \mu \mathrm{L}$ of lysis buffer $\left(10^{6}\right.$ cells $\left./ \mathrm{mL}\right)$ and viral RNA was extracted from lysed whole cell samples. The positive strands of the $5^{\prime}$ non-translated region $\left(5^{\prime} \mathrm{NTR}\right)$ of the HAV genome were amplified. This region was selected as the target due to its sequence conservation. The positive strands were reverse-transcribed using Superscript III reverse transcriptase (Invitrogen, Carlsbad, CA). The reaction was conducted at $50^{\circ} \mathrm{C}$ for $1 \mathrm{~h}$, followed by incubation for $10 \mathrm{~min}$ at $65^{\circ} \mathrm{C}$ in a $20 \mu \mathrm{L}$ volume containing $10 \mu \mathrm{L}$ of RNA $(10 \mathrm{pg}-5 \mu \mathrm{g}), 10 \mathrm{pmol} / \mu \mathrm{L}$ anti-sense primer (HAV5NCRI-R) (Table), 1 U/ $\mu$ L RNasin (Promega, Mad-

TABLE

Reproducibility analysis of the ensyme immunoassay (EIA) and real-time (RT)-polymerase chain reaction assays and correlation between hepatitis A virus (HAV) particles and HAV genomes

\begin{tabular}{lccccccc}
\hline $\begin{array}{l}\text { Day } \\
\text { (dpi) }\end{array}$ & Dilution & $\begin{array}{c}\text { Real-time } \\
(\text { copies/mL) }\end{array}$ & $\begin{array}{c}\text { CV\% } \\
(\mathrm{RT})\end{array}$ & $\begin{array}{c}\text { EIA } \\
(\mathrm{OD})^{b}\end{array}$ & $\begin{array}{c}\text { CV\% } \\
(\mathrm{RT})\end{array}$ & $\mathrm{R}^{c}$ & $\mathrm{p}(95 \% \mathrm{CI})^{d}$ \\
\hline 7 & $1 / 1$ & $3.180 \pm 30.2$ & 0.9 & $0.819 \pm 0.028$ & 3.5 & 0.969 & $<0.0001(85.6-99.3)$ \\
& $1 / 5$ & $201.0 \pm 3.0$ & 1.5 & $0.46 \pm 0.01$ & 4.1 & - & - \\
& $1 / 10$ & $89.0 \pm 1.0$ & 1.1 & $0.33 \pm 0.103$ & 3.0 & - & - \\
10 & $1 / 1$ & $111.333 \pm 2.309 .4$ & 5.2 & $2.29 \pm 0.04$ & 1.9 & 0.853 & $0.003(43.6-96.8)$ \\
& $1 / 5$ & $84.833 .3 \pm 2.914 .3$ & 3.4 & $1.199 \pm 0.05$ & 4.7 & - & - \\
14 & $1 / 10$ & $707.3 \pm 34.5$ & 4.8 & $0.87 \pm 0.06$ & 7.5 & - & - \\
& $1 / 1$ & $11.233 .3 \pm 404.1$ & 3.3 & $2.34 \pm 0.1$ & 4.4 & 0.784 & $0.012(25.1-95.2)$ \\
& $1 / 5$ & $205.6 \pm 13.6$ & 6.6 & $1.80 \pm 0.13$ & 7.5 & - & - \\
\end{tabular}

$a$ : mean \pm standard deviation (SD) of triplicate analyses; $b$ : media $\pm \mathrm{SD}$ of triplicate analyses; $c$ : correlation coefficient between RT and EIA; $d$ : two-tailed $\mathrm{p}<0.05$ was considered statistically significant; CI: confidence interval; CV: coefficient of variation; dpi: days post-infection; OD: optical density. 
ison, WI), $125 \mathrm{mM}$ of each deoxynucleoside triphosphate and $1 \mathrm{U} / \mu \mathrm{L}$ Superscript III reverse transcriptase. After cDNA synthesis, a master mix containing $1 \times$ TaqMan Universal PCR Master Mix (Applied Biosystems, Hammonton, $\mathrm{NJ}$ ) and $1.25 \mu \mathrm{L}$ of the assay mixture ( $300 \mathrm{nM}$ of each primer, $150 \mathrm{nM}$ probe) (Applied Biosystems Assay, Foster City, CA) was prepared on ice. Five microlitres of cDNA and standard curve points were added to $20 \mu \mathrm{L}$ of the PCR master mix. The thermal cycling conditions included an initial step at $50^{\circ} \mathrm{C}$ for $2 \mathrm{~min}, 95^{\circ} \mathrm{C}$ for $10 \mathrm{~min}$, 40 cycles of $95^{\circ} \mathrm{C}$ for $15 \mathrm{~s}$ and $60^{\circ} \mathrm{C}$ for $1 \mathrm{~min}$. The primers and probe used to quantify the $5^{\prime} \mathrm{NTR}$ are described by de Paula et al. (2007).

Statistical analysis - All graphs were generated using GraphPad Prism software 5.0. Data are presented as the mean and standard deviation of triplicates for the RT and ensyme immunoassay (EIA) values. The statistical significance of the linear (Pearson) correlation between the methods was determined, with a $p$ value $<0.05$ considered significant. An analysis of variance was used to evaluate significant differences between the values of each group.

\section{RESULTS}

Correlation between the number of HAV particles and the HAV genome - To determine a relative correlation between the number of HAV genomes and HAV particles, which could be used as a replacement to traditional viral titration methods, we quantified the virus by the standard method of titration (ELISA in situ) and a molecular test (RT-PCR) and used a statistical approach to test correlations. The number of HAV (HAF-203) particles in the three different stocks was determined by ELISA in situ and compared with the viral load measured by RT-PCR (Fig. 1). From days 7-10, there was a significant increase in detection of HAV genome and particles by RT and EIA, respectively $(\mathrm{p}<0.001)$. However, from day $10-14$, there was a significant decrease in genome detection $(\mathrm{p}$ $<0.001$ ) and a stabilization of HAV particles (Fig. 1). At 10 days post-infection, the maximum concentration of HAV RNA was reached in all stocks $\left(10^{5}\right.$ copies $\left./ \mathrm{mL}\right)(\mathrm{p}$ $<0.001)$, while the highest number of HAV particles was observed at day 14 (optical density $=2.4, \mathrm{p}<0.001$ ). A linear correlation analysis showed a strong positive correlation between the number of $\mathrm{HAV}$ particles and number of HAV genomes $(r=0.96, p<0.0001)$ at seven days postinoculation (Table). After 10 and 14 days of incubation, the linear correlation analysis showed a weak positive correlation between HAV particles and HAV genomes ( $\mathrm{r}$ $=0.85$ and 0.784 , respectively) (Table).

Relationship between the titre of infectious HAV and RNA copies - The titre of infectious HAV at seven, 10 and 14 days post-infection (dpi) was estimated by endpoint titration using $\mathrm{TCID}_{50}$. The highest $\mathrm{TCID}_{50}$ value occurred on day 7 using serial one-fold dilutions $\left(10^{-6.167}\right)$. The cycle threshold $(\mathrm{Ct})$ values for each day of infection were measured and correlated with $\mathrm{TCID}_{50}$ (Fig. 2). This analysis demonstrated that there was a significant correlation between titre equivalent values, measured by RT-PCR and TCID $_{50}$ titres. This correlation allowed the calculation of the number of RNA copies corresponding with the $\mathrm{TCID}_{50}$.

Analyses of assays accuracy - To test the reproducibility of the EIA and RT-PCR assays, the assays were conducted in triplicate using different aliquots (1:1, 1:5 and 1:10) of the same stock. In addition, the assays were performed three times as an inter-assay analysis. The low variations in the EIA (with a coefficient of variation ranging from 3-7.5\%) and RT-PCR (with a coefficient of variation ranging from $0.9-6.6 \%$ ) demonstrated the reproducibility of the tests (Table).

\section{DISCUSSION}

Over the last few decades, several types of inactivated HAV vaccines have been developed. The vaccines are whole-virus preparations produced by the growth of HAV strains in cell culture, followed by inactivation of the virus. HAV grows poorly in cell culture and does not generally induce a cytopathic effect. The viral load can be quantified by TCID $_{50}$ determination or RT-PCR. In this study, a statistical approach was used to verify the correlation between the number of particles and number of HAV RNA copies.
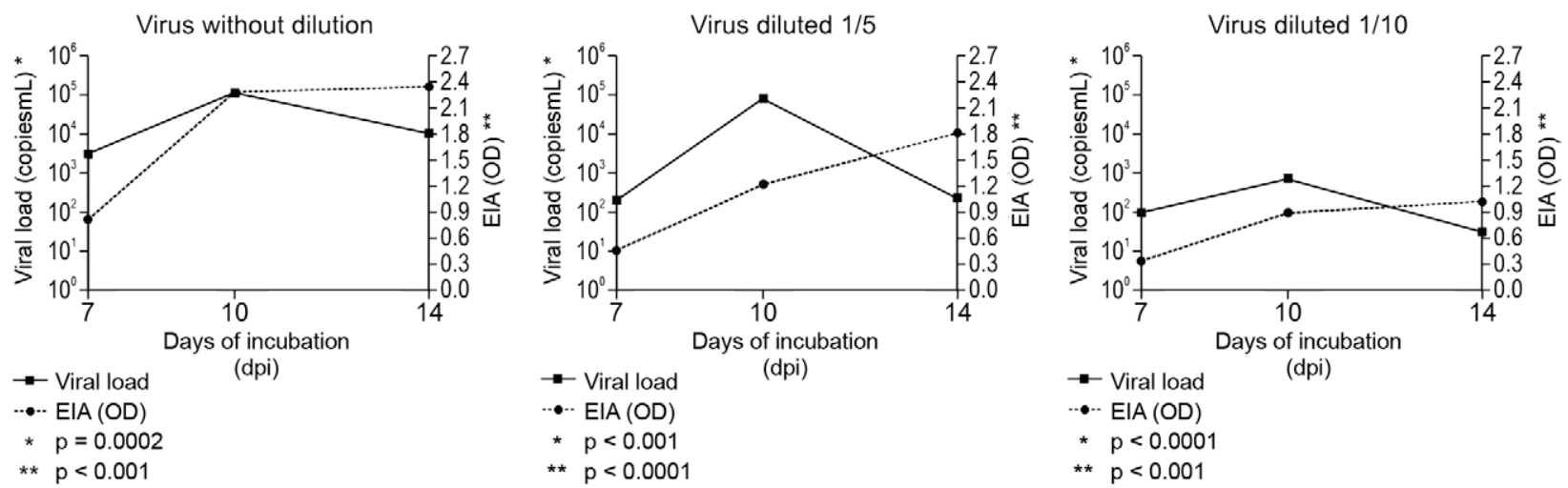

Fig. 1: comparison between the numbers of viral particles analyzed by ELISA in situ and the number of amplified copies of the genome of hepatitis A virus analyzed by real-time (RT) polymerase chain reaction according to the days of incubation. dpi: days post-infection; EIA: ensyme immunoassay; OD: optical density; *: analysis of variance of RT values; **: ELISA values. 
The number of HAV particles was estimated by EIA and this value was compared with the number of HAV genomes determined by RT-PCR (Fig. 1). The maximum concentration of HAV RNA was reached at $10 \mathrm{dpi}$ and the highest number of HAV particles was observed at 14 dpi. However, at seven days post-incubation, there was a strong significant positive correlation $(\mathrm{r}=0.969, \mathrm{p}<$ 0.001 ) between the number of particles and number of HAV genomes (Table) for all three stocks, which suggests that there is a statistical correlation between the number of HAV genomes and the infectivity. A possible explanation for this result is that at seven days post-infection, the new HAV genomes are predominantly encapsidated to generate mature virions instead of being used as templates for HAV genome replication. This correlation enabled the calculation of the number of RNA copies in a sample and the association with TCID $_{50}$, as described recently for enterovirus. For enterovirus, the RT data were correlated over a wide range of viral concentrations with the titre obtained by endpoint titration (Jonsson et al. 2009). Our results are in accordance with Villar et al. (2004), who reported that at 14 days of incubation, there was a higher optical density by ELISA in situ, while the highest HAV titre was observed at seven dpi.

From days 7-10, there was a significant increase in the detection of both the HAV genome and particles by RT and EIA $(p<0.001)$. This suggests that during this period, most of the new HAV genomes synthesized are encapsidated to generate virions. Linear correlation analysis showed that there was a weak positive correlation between the $\mathrm{TCID}_{50}$ and the number of HAV genomes at 10 and 14 days post-infection. From days 1014 , there was a significant decrease in genome detection $(p<0.001)$ and a slight increase of the number of HAV particles. While these results did not provide biochemical or virological evidence of the presence of defective particles, we speculate that during this period, a higher number of procapsids or empty particles are present in the viral stocks, likely due a reduced rate of genome replication and predominant use of the genome to produce viral protein as mRNAs to produce viral proteins.

To evaluate the reproducibility of the tests, all ELISAs and RT-PCR assays were conducted in triplicate.
The coefficients of variation were lower than $10 \%$, which demonstrates the reproducibility of the tests.

In a previous study, the density and sedimentation analyses of extracts from cells infected with HAV at 21 days revealed that the virion itself usually represented less than $50 \%$ of the total mass of the viral antigen. A major portion of the antigen was associated with noninfectious, empty particles (Ruchti et al. 1991). Replication-defective mutant viruses are essential for viral genome replication or synthesis and the assembly of viral particles. These mutant viruses possess the advantages of both classical types of viral vaccines because these mutant viruses are as safe as inactivated viruses, but express viral antigens inside infected cells so that major histocompatibility complex class I and class II presentation can occur efficiently. Replication-defective viruses have served both as vaccines for the parent virus and as a vector for the expression of heterologous antigens. Additionally, these replication-defective viruses have also served as important probes of the host immune response by helping define the importance of the first round of infected cells in the host immune response, the mechanisms of activation of the innate immune response and the role of the complement pathway in humoural immune responses to viruses (Dudek \& Knipe 2006).

In this study, we demonstrated that the number of defective HAV particles in cell culture at 14 days should be considered. The linear correlation analysis suggested that varying amounts of defective particles can modulate the results of HAV quantification by ELISA or RTPCR. On the first day of infection, the replication cycle occurred normally and progeny virions were produced. However, these virions were non-infectious and thus, the infection did not spread to a second round of cells. The released, non-infectious virions may provide inert antigen that can spread beyond the infected cells; nevertheless, the blockage of spreading may not be complete for all viruses (Loudon et al. 2001). For this reason, stocks of RNA viruses can contain different mixtures of infectious and defective particles that are indistinguishable by ELISA in situ because the surfaces of both particles share the same immunoreactivity (Handke et al. 2009). Generally, only the number of infectious virions in the
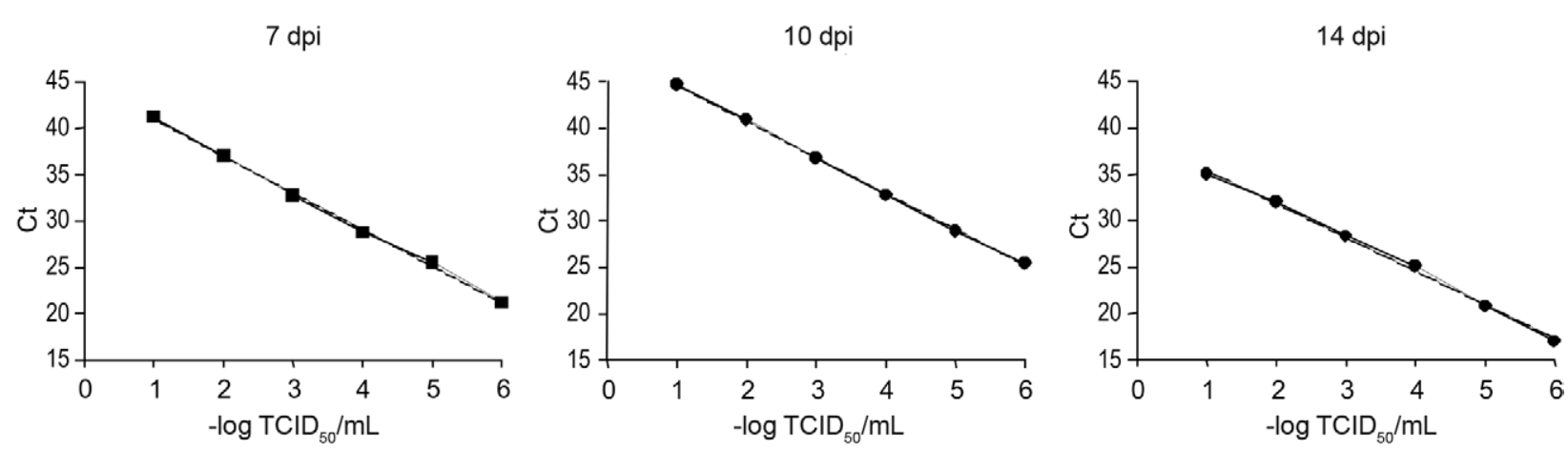

Fig. 2: correlation of the amounts of hepatitis A virus particles and RNA, estimated by tissue culture infective dose $\left(\mathrm{TCID}_{50}\right)$ and cycle threshold $(\mathrm{Ct})$ values of real-time polymerase chain reaction. dpi: days post-infection. 
reference stocks is of interest and the quantity of defective particles is neglected. The relative number of defective particles can be at least five-fold higher in the stock with the lowest titre compared with the stock with the highest titre (Handke et al. 2009).

To further determine whether the viral titre was correlated with the calculated $\mathrm{Ct}$ value from RT-PCR, titres of HAV-containing stocks were estimated by endpoint titration. The RT data were correlated over a wide range of viral concentrations with the HAV titre obtained by $\mathrm{TCID}_{50}$ (Fig. 2). This correlation enabled the calculation of the number of RNA copies in a sample and the association with $\mathrm{TCID}_{50}$, as described recently for enterovirus (Jonsson et al. 2009).

The need for a virus quantification assay is particularly important to determine viral quantities, follow HAV growth in cell culture and establish the quantity of antigen for diagnostic assays and inactivation. The results reported here indicate that the duration of HAV growth in cell culture must be taken into account when correlating the quantification methods. At seven days post-infection, a correlation between the quantity of HAV genomes determined by RT-PCR and the number of HAV particles determined by ELISA in situ was observed. It was also demonstrated here that titre equivalents generated by RT-PCR correlated with the titres obtained by the endpoint dilution method, which implies that RT-PCR may be a feasible, faster alternative assay to estimate HAV titres at approximately 10 days post-infection. The results for 14 days post-infection imply that defective particles in viral stocks should be considered when performing virus quantification assays.

\section{REFERENCES}

de Paula VS, Diniz-Mendes L, Villar LM, Luz SL, Silva LA, Jesus MS, da Silva NM, Gaspar AM 2007. Hepatitis A virus in environmental water samples from the Amazon Basin. Water Res 41: 1169-1176.

de Paula VS, Perse AS, Amado LA, de Morais LM, de Lima SM, Tourinho RS, Gaspar AM, Pinto MA 2009. Kinetics of hepatitis A virus replication in vivo and in vitro using negative-strand quantitative PCR. Eur J Clin Microbiol Infect Dis 28: 1167-1176.

Donia D, Bonanni E, Diaco L, Divizia M 2009. Statistical correlation between enterovirus genome copy numbers and infectious viral particles in wastewater samples. Lett Appl Microbiol 50: 237-240.

Dudek T, Knipe DM 2006. Replication-defective viruses as vaccines and vaccine vectors. Virology 344: 230-239.

Forcic D, Kosutic-Gulija T, Santak M, Jug R, Ivancic-Jelecki J, Markusic M, Mazuran R 2009. Comparisons of mumps virus potency estimates obtained by $50 \%$ cell culture infective dose assay and plaque assay. Vaccine 28: 1887-1892.
Handke W, Kruger DH, Rang A 2009. Defective particles can lead to underestimated antibody titers in virus neutralization tests. Intervirology 52: 335-339.

Jonsson N, Gullberg M, Lindberg AM 2009. Real-time polymerase chain reaction as a rapid and efficient alternative to estimation of picornavirus titers by tissue culture infectious dose $50 \%$ or plaque forming units. Microbiol Immunol 53: 149-154.

Khatib R, Chason JL, Silberberg BK, Lerner AM 1980. Age-dependent pathogenicity of group B coxsackieviruses in Swiss-Webster mice: infectivity for myocardium and pancreas. J Infect Dis 141: 394-403.

Konduru K, Virata-Theimer ML, Yu MY, Kaplan GG 2008. A simple and rapid hepatitis A virus (HAV) titration assay based on antibiotic resistance of infected cells: evaluation of the HAV neutralization potency of human immune globulin preparations. Virol J 155: 155.

Leland DS, Ginocchio CC 2007. Role of cell culture for virus detection in the age of technology. Clin Microbiol Rev 20: 49-78.

Lemon SM, Binn LN, Marchwicki RH 1983. Radioimmunofocus assay for quantitation of hepatitis A virus in cell cultures. J Clin Microbiol 17: 834-839.

Loudon PT, Blakeley DM, Boursnell ME, Day DA, Duncan IA, Lowden RC, McLean CS, Martin G, Miller JC, Shaw ML 2001. Preclinical safety testing of DISC-hGMCSF to support phase I clinical trials in cancer patients. J Gene Med 3: 458-467.

Minor P 1991. Picornaviridae. In RIB Francki, CM Fauquet, DL Knudson (eds.), Classification and nomenclature of viruses (Arch Virol Suppl 2), Springer-Verlag, Wien, p. 320-326.

Provost PJ 1979. Propagation of human hepatitis A virus in cell culture in vitro. Proc Soc Exp Biol Med 160: 213-221.

Purcell RH, Wong DC, Moritsugu Y, Dienstag JL, Routenberg JA, Boggs JD 1976. A microtiter solid-phase radioimmunoassay for hepatitis A antigen and antibody. J Immunol 116: 349-356.

Reed LJ, Muench IL 1938. A simple method for estimating fifty per cent endpoints. Am J Hyg 27: 493-497.

Richards GP, Watson MA 2001. Immunochemiluminescent focus assays for the quantitation of hepatitis A virus and rotavirus in cell cultures. J Virol Methods 94: 69-80.

Ruchti F, Siegl G, Weitz M 1991. Identification and characterization of incomplete hepatitis A virus particles. J Gen Virol 72: 2159-2166.

Siegl G 1982. Structure and biology of hepatitis A virus. In HAJM Szmuness (ed.), Viral hepatitis, Franklin Institute Press, Philadelphia, p. 13-20.

Siegl G, de Chastonay J, Kronauer G 1984. Propagation and assay of hepatitis A virus in vitro. J Virol Methods 9: 53-67.

Villar LM, Amado LA, Gaspar AM 2004. In situ enzyme immunoassay for titration of a Brazilian hepatitis A virus strain (HAF-203). Braz J Med Biol Res 37: 1023-1027.

Wheeler CM, Fields HA, Schable CA, Meinke WJ, Maynard JE 1986. Adsorption, purification and growth characteristics of hepatitis A virus strain HAS-15 propagated in fetal rhesus monkey kidney cells. J Clin Microbiol 23: 434-440. 